\title{
Reducing status quo bias in choice experiments
}

\author{
OLE BONNICHSEN ${ }^{1, *}$ \\ JACOB LADENBURG $^{2}$
}

${ }^{1}$ Department of Food and Resource Economics (IFRO), University of Copenhagen, Denmark

${ }^{2}$ Danish Institute for Local and Regional Government Research (KORA), Denmark

\begin{abstract}
To secure the validity and applicability of stated preference measures in economic analysis, hypothetical preferences must mimic real life preferences. For instance, people have a propensity to prefer what they already have when presented with alternatives that, all things being equal, seem to be superior, i.e. a status quo effect. However, in the stated preference literature, the tendency to choose the alternative representing the status quo situation seems to exceed real life status quo effects. Accordingly, status quo bias can be a problem. In the Choice Experiment literature, status quo bias is found to be a function of protest attitudes concerning the payment of the hypothetical good. In a split sample framework we test an ex-ante entreaty aimed at reducing payment based protest attitudes. We find that the entreaty reduces status quo bias and improves the internal validity of stated preferences in our data based on Swedish ostomates' preferences for ostomy pouch quality changes.
\end{abstract}

JEL Classification: C13, C33, C52, C99

Key words: stated preference, choice experiment, status quo bias, entreaty

\section{Introduction}

When applying Willingness-To-Pay (WTP) measures from stated preference surveys in health economic analysis, the necessity for a strong validity of the estimated gains for welfare improvements is highly important (Louviere and Lancsar, 2009; Vanleene et al., 2008). Consequently, researchers and practitioners are faced with the challenge of framing stated preference surveys so that the hypothetical market for health mimics the potential real life choice situation had the health good in question been marketable. This would establish a realistic setup for the valuation questions, which is more familiar to people and thereby minimise the level of potential biases reported in the literature to have a significant influence on stated preferences.

One critical bias is status quo (SQ) bias (Samuelson and Zeckhauser, 1988). It is a cognitive bias, where the current endowment or policy acts as a reference point where changes away from it are associated with a loss. Consequently, when an individual is confronted with a choice, he/she puts undue weight on the alternative representing the current policy situation/existing bundle of goods/own good (SQ alternative), relative to alternatives representing changes from this SQ alternative. As illustrated in the case of organ donation, Johnson and Goldstein (2003) found evidence that the propensity to be an organ donor was nearly twice as high, when organ donation was the SQ alternative compared to when the SQ alternative was no organ donation. Similar examples are found

* Correspondence to: Ole Bonnichsen, Environmental and Natural Resource Economics Unit, Department of Food and Resource Economics (IFRO), Faculty of Science, University of Copenhagen, Rolighedsvej 23, 1958 Frederiksberg C, Denmark; Phone: +45 35336815; Fax: +45 35336802; E-mail: ole@,ifro.ku.dk 
in Probst et al. (2013) in relation to the ordering of laboratory test practices for paediatric patients and Chapman et al. (2010) in relation to influenza vaccination. In all the mentioned cases, the SQ alternative acts as a threshold, which the gain/benefit of a choice away from the SQ situation must exceed, in order for the individual to make that choice. As a result, a relatively larger share of choices of the SQ alternative is observed and the true value of a health change becomes difficult to identify. Taken at the extreme, SQ bias could make preferences elicited from stated preference surveys for future health policies as well as research and development of new health treatments irrelevant, if respondents in the stated preference survey are hesitant to make choices away from their current flow of health services, and therefore state a zero or even negatively biased value of a proposed positive change in the health service. Motivated by the relevance of understanding the motivation to state SQ biased preferences, Meyerhoff and Liebe (2009) find that SQ choices can be related to peoples' objection to pay for changes in the good in focus. This is also known as protest attitudes against the attribute that represents variation in the cost/price of the alternative (cost attribute). This attribute captures the marginal value associated with a decrease in income, which will occur if an alternative is chosen. In the Meyerhoff and Liebe (2009) Choice Experiment, the choice behaviour is less related to whether a gain can be made by choosing a non-SQ situation. Naturally, their applied stated preference survey is different compared to the above mentioned studies in the sense that those studies test the effect of varying the SQ alternative, whilst Meyerhoff and Liebe (2009) keep the SQ alternative constant. However, the consequence of SQ bias on the estimated preference relations is the same. A SQ bias results in an underestimation of the welfare changes of a proposed policy change. Secondly, given that the SQ alternative is chosen too frequently, information regarding the relative values between different types of health services associated with a policy change is reduced. This reduces the effectiveness of stated preference surveys to elicit and identify preferences.

Our paper tests the effect of a small entreaty aimed at reducing protest attitudes towards the payment for improvements and thus potentially reducing potential SQ bias in a Choice Experiment eliciting Swedish ostomy patients' (henceforth called ostomates) preferences. We test the entreaty by comparing preferences between two treatment groups; treatment A (not receiving the entreaty) and treatment B (receiving the entreaty). The Choice Experiment approach presents the ostomates with a series of choice sets each consisting of a number of alternatives. In our case we present the respondents with a choice between two hypothetical ostomy pouch alternatives and a SQ alternative representing their current ostomy pouch system.

The paper is structured as follows: In the next section the methodology and the survey related to testing our entreaty to reduce SQ bias is presented. This is followed by a theoretical presentation of SQ bias and mitigation thereof, the econometric models applied, results and a conclusion.

\section{The choice experiment}

The Choice Experiment method presents survey respondents with a hypothetical market for the good or service in focus and asks them to choose between two or more alternative compositions of the good or service in a series of choice sets. In accordance with Lancaster's attribute theory of value (Lancaster, 1966), the alternatives define the good or service in terms of their key attributes, and different alternatives are described by varying the levels of the attributes. By examining the trade-offs between attributes and attribute levels that are implicitly revealed in the choices made by respondents, it is possible to derive an estimate of the utility associated with the different attributes. If one of the 
attributes is measured in monetary units (i.e. costs), it is possible to derive estimates of respondents' WTP for the other attributes from the marginal rate of substitution between the monetary attribute and the other attributes (Louviere et al., 2000).

The survey used in the present study elicited preferences for changes in attributes of ostomy pouches among Swedish ostomates. Prior to the choice sets, the respondents were presented with a scenario description, which described different types of changes to an ostomy pouch. The scenario introduced improvements to the current ostomy pouch with regard to three different attributes of an ostomy pouch: The flexibility of the system as a whole, the number of small starting leakages under the base plate per month and the filter lifetime. An additional monthly expense ${ }^{1}$ was used as the payment vehicle of the cost attribute. Attributes and their levels were chosen on the basis of stoma management appliance literature (e.g. Nugent et al., 1999; Silva et al., 2003), numerous interviews with experts working within the medical devices field, a focus group, and a pilot survey. The focus group was used to ensure that the best attribute levels in the design should all be improvements over the current ostomy pouch for the majority of respondents. Similarly, the lowest levels of the cost attribute were kept small to ensure that the respondents could find the improvements in the hypothetical alternatives to be worth the additional costs. For more specifics on how the focus group and pilot survey were conducted as along with their findings, please refer to Bonnichsen (2011). Also included in the scenario description given to respondents was a presentation of the attributes, reasons for the variations in the attribute levels, a standard Cheap Talk script focusing on the issue of hypothetical bias ${ }^{2}$ and budget reminders prior to the choice session (Carlsson and Martinsson, 2001; List and Gallet, 2001; Ozdemir et al., 2009). The attributes were presented to the respondents with the descriptions shown in Table 1.

Table 1: Attributes and attribute levels

\begin{tabular}{ll}
\hline Attribute & Attribute level \\
\hline \multirow{2}{*}{ Flexibility of the system as a whole } & Same as current \\
\hline Number of small starting leakages & Small improvement \\
Large improvement
\end{tabular}

\footnotetext{
${ }^{1}$ Ostomates paid a maximum of 1,800 SEK per year for their pouches at the time the survey was conducted, and any payments beyond this amount are reimbursed.

${ }^{2}$ A Cheap Talk script highlights to the respondent that there exists a tendency to overstate how much people are willing to pay in hypothetical surveys, and that the respondent should be sure, that he/she is willing and able to pay the cost associated with the chosen alternatives.
} 
The experimental design defining the combination of the mentioned attribute levels into alternatives and choice sets was identified following Kuhfeld (2010) and using SAS to construct statistically efficient choice designs (Zwerina et al., 2010). As a full factorial design comprised $162(3 \times 3 \times 3 \times 6)$ possible alternatives, a D-optimal fractional factorial design consisting of 18 experimentally generated alternatives was identified using the SAS macro '\%mktruns'. These alternatives were then arranged into nine choice sets using the macro '\%choiceeff' and assigned into two blocks using the '\%mktblock' macro. The design was not utility balanced. Accordingly, it was not a criterion for the design that an alternative within each choice set would be equally attractive in terms of the total quality of the ostomy pouch and the additional expense. However, the arrangement of alternatives in each choice set ensured that the attribute levels had a minimum overlap (minimised the risk of for example both alternatives in the choice set having an additional expense of 500 SEK) and that each attribute level occurred an equal number of times across all alternatives (level balance). Though a more efficient design could have been obtained, the present design should make it easier for respondents to choose (compared to a utility balanced design). We perceive this as a benefit in the study design, as the choice of the SQ alternative is thereby not confounded with respondents' cognitive difficulties related to the choice among alternatives that could otherwise occur in a utility balanced design where alternatives have a more equal utility. The alternatives were then arranged into 9 choice sets and assigned into two blocks, with the respondents in the two treatment groups randomly allocated into the blocks consisting of five and four choice sets per block. It was thereby ensured that the respondents in the two treatments had an equal probability to make choices from either block of choice sets. Figure 1 shows an example of a choice set used in the questionnaire.

Figure 1: Choice set example

\begin{tabular}{|c|c|c|c|}
\hline & Alternative 1 & Alternative 2 & $\begin{array}{c}\text { My current system } \\
\text { (i.e. no change) } \\
\end{array}$ \\
\hline $\begin{array}{l}\text { Flexibility of the system as a whole } \\
\text { (base plate and coupling) }\end{array}$ & Large improvement & Same as current & - \\
\hline $\begin{array}{l}\text { Number of small starting leakages } \\
\text { under the base plate per month }\end{array}$ & 3 leakages & No leakages & - \\
\hline Filter lifetime & 24 hours & 12 hours & - \\
\hline Additional expense per month & $750 \mathrm{SEK}$ & $200 \mathrm{SEK}$ & 0 SEK \\
\hline \multirow[t]{2}{*}{ I prefer } & $\square$ & $\square$ & $\square$ \\
\hline & \multicolumn{2}{|c|}{$(m a r k$} & $\rho n l y)$ \\
\hline
\end{tabular}

A choice set consisted of three alternatives: The SQ alternative with no additional monthly expense and two policy generated improvement alternatives, which represent variations in the present pouch with regards to the three quality attributes and an associated additional monthly expense. Following Banzhaf et al. (2001), the SQ alternative included in the choice sets was defined by the current system of the individual. The attribute levels of filter lifetime and number of leakages were filled in by the respondent prior to the choice 
sets and this information was then used to define the SQ in estimation. In relation to testing the effect of the entreaty it should be made clear that the questionnaires for both treatments were kept identical, with the exception that respondents in treatment B were given the entreaty, while respondents in treatment A were not. As it will be presented in the next section, the focus of the present paper is the potential excess choices of the SQ alternative, i.e. SQ bias.

\section{Status quo bias and mitigation thereof}

When asking a group of respondents to state their preferences for a change in for example improvements in health services, SQ bias increases the number of choices that reflect a preference for keeping the existing health service level, vis-à-vis reducing the number of choices for changes in the health service. Theoretically, SQ bias emerges if a positive utility related to the SQ alternative acts as a larger threshold, which the non-SQ alternative(s) must exceed before they are chosen, compared to that threshold on a real market. SQ bias is thus fundamentally different from an $S Q$ effect, which represents the rational and objective positive utility of the SQ alternative that can be related to loss aversion or uncertainty regarding the change from the SQ to a non-SQ alternative ${ }^{3}$.

As suggested by Meyerhoff and Liebe (2009), Kahneman et al. (1991) and Boxhall et al. (2009), SQ bias is related to different elements in the hypothetical market used to elicit preferences for the good in question, such as mistrust in the providing organisation, protest votes against the survey as well as the number of attributes and attribute level differences. Kataria et al. (2012) find that that their respondents perceiving the quality of the SQ alternative as being better and interestingly also worse than the non-SQ alternatives, choose the SQ alternative more frequently, compared to the respondents who find the described quality credible. In the case of perceiving the SQ alternative as worse, one may expect respondents to make fewer SQ choices. Accordingly, their results suggest that disbelief in the description of the SQ alternative can make respondents react by choosing the SQ alternative more often. Finally, Meyerhoff and Liebe (2009) find evidence that the number of SQ choices are positively influenced by the degree that people object to paying in a stated preference survey (i.e. a protest attitude towards the cost attribute).

In the remaining part of the paper, we focus on the payment based protest attitude and the impact on SQ choices. This focus is motivated by the cost attribute essentially being the link between relative preferences for different attributes and the assessment of the value of attributes in the traditional price-demand space. Without a cost attribute, it is in principle impossible to deduce the economic values. As mentioned, the findings of Meyerhoff and Liebe (2009) indicate that the propensity to choose the SQ alternative increases significantly when the respondent has a stronger protest attitude towards the payment of the hypothetical change in the good. This suggests a potential solution to reduce SQ bias induced by protest attitudes towards the payment. If the level of protest attitude can be reduced, we would expect the propensity to choose the SQ alternative also to be reduced.

Following Meyerhoff and Liebe (2009), they estimate an individual payment based protest attitude, $p_{n}$. This is done by summing over the individual $n$ 's stated attitude $\left(p_{n k}\right)$

\footnotetext{
${ }^{3}$ In the present study we expect small SQ effects in the sense that respondents in the stated preference study do not choose between physically different ostomy pouches, but pouches with different quality attributes in relation to various features of the system. The ostomates were thus also explicitly instructed to consider only the ostomy pouch attributes presented to them in the experiment, when making their choice of ostomy pouch and as such not to make a choice between their own and new ostomy pouches.
} 
towards $k$ questions that the respondents answer in order to measure the level of protest attitude, so that $p_{n}=\sum_{k=1}^{K} p_{n k}$. The authors refer to this as the cumulative payment based protest attitude. Accordingly, the propensity to state a SQ biased preference is an increasing function of $p_{n}$ :

$$
\partial S Q_{-} \text {bias }_{n} / \partial p_{n}>0
$$

Therefore, the higher the level of payment based protest attitude, the higher the level of SQ bias. In their paper, this relation between $p_{n}$ and SQ bias is estimated by interacting the cumulative payment based protest attitude with the alternative specific constant (ASC) for the SQ alternative. The ASC for the SQ alternative is a dummy variable that controls for the utility associated with the SQ alternative relative to the hypothetical alternatives in Choice Experiments. Meyerhoff and Liebe (2009) find that the numerical size of the estimated coefficient for the ASC is positively related to the level of protesters, which suggests a SQ bias relation. This denotes that:

$$
\partial A S C_{S Q, n} / \partial p_{n}>0
$$

Reductions in the protest attitude towards the cost/payment attribute in Choice Experiments should thus have a positive influence on the level of SQ bias.

Accordingly, in order to reduce the payment based protest attitude, it is necessary to define the presentation of the hypothetical market (scenario description) in a way that makes the respondents accept the cost attribute. A well-defined and thoroughly developed scenario description, which gives a fair and trustworthy presentation of the cost attribute and choice of payment vehicle, is expected to mitigate a payment based protest attitude. However, inspired by Cheap Talk scripts/entreaties used to reduce hypothetical bias in stated preference surveys (Cummings and Taylor, 1999), it might be necessary to extend the wording in the scenario description and specifically address potential protest issues related to the cost attribute in order to obtain a higher mitigation of the payment based protest attitudes and the associated SQ bias.

We therefore conducted an experiment to test the effect of an ex-ante entreaty aimed at reducing cost/payment related protest attitudes and reduce potential SQ bias in a Choice Experiment survey used to elicit preferences for ostomy pouch attributes. The advantage of using an entreaty is the possibility to focus the attention of the respondents onto the choice task before they state their preferences. However, as highlighted in the vast Cheap Talk literature, the effect of an entreaty is contingent on the respondents actually reading, understanding and remembering the wording in the entreaty. In this perspective, Cheap Talk has not been the remedy of hypothetical bias, despite the promising findings in Cummings and Taylor (1999). As stressed in the Cheap Talk literature, an entreaty might only influence preferences of specific subgroups (Aadland and Caplan, 2003; Aadland and Caplan, 2006, Ami et al., 2011; List, 2001; Lusk, 2003), such as female respondents (Barrage and Lee, 2010; Ladenburg et al., 2011; Mahieu, 2010). In addition, the wording of the entreaty might be too powerful (Morrison and Brown, 2009), too weak (Ami et al., 2001; Nayga et al., 2006; Blumenschein et al., 2008) or even have the opposite effect on preferences than intended (Aadland and Caplan, 2006; Carlsson et al., 2011). When using an entreaty in Choice Experiments, where the respondents state their preferences through a series of choice tasks, Ladenburg and Olsen (2014) and Ladenburg (2014) also stress that the respondents might forget the information included in the entreaty when they make their choices. 
The tested entreaty in the present paper directly focuses the attention of the respondent towards the payment of the good by stressing that payment is included to increase the realism of their choice and for them to convey how much they perceive an improvement is worth, but also that they should consider the hypothetical payment as being real. Referring to the Cheap Talk literature, we acknowledge that applying a designed entreaty to mitigate, in our case, protest behaviour related to the cost attribute is a delicate balance between on one hand making the respondent less offensive towards the cost attribute, and on the other hand not decreasing the incentive compatibility of their stated preferences. For example, Morrison and Brown (2009) find that Cheap Talk overcalibrates WTP and pushes the demand curve too far inwards relative to the real demand curve. A perhaps even better illustration is Bosworth and Taylor (2012) who find that Cheap Talk overcalibrates preferences on the intensive margin of choice (WTP for changes in the attributes), but undercalibrates preferences on the extensive margin of choice (the choice of purchase of a good). In this light, it is fair to raise the concern that the effect of the entreaty should not be too strong, so that the respondents become insensitive to changes in the cost attribute and may disregard it as well as the SQ alternative. However, besides softening up the perception of the cost attribute, the wording of our entreaty should also make the respondent take the cost attribute into account. We therefore do not expect this to be a problem in our data, as also supported by our results in section 6 . Here we show that the respondents who were presented with the entreaty have stated significantly negative preferences for an increase in the price vector, and have also stated positive and significant preferences for the SQ alternative, as well as having generally lower levels of WTP compared to the respondents who were not given the entreaty. Furthermore, the entreaty should not be too dominant relative to the part of the scenario description presenting the setup of the Choice Experiment and the attributes of the pouches. The entreaty was therefore kept short compared to for example the original Cheap Talk in Cummings and Taylor (1999). Accordingly, we can expect that the entreaty actually has been read by the respondents and thus potentially affects all respondents. The applied entreaty is presented below.

"The hypothetical expense presented to you in the next questions is not an expense that you yourself will be responsible for paying, but it has been included merely to increase the realism of your choices and for you to convey how much you believe an improvement is worth. While this hypothetical expense will have no effect on the reimbursements received in Sweden and will not result in any extra cost for ostomates, we kindly ask you to carefully consider the hypothetical expense, as if you were to pay it when making your choices."

The wording of the entreaty thus directly addresses the key aspects of the type of protest attitudes identified in Meyerhoff and Liebe (2009). As such, it is expected that the entreaty reduces protest behaviour, such that:

$$
\partial p_{n} / \partial E n t r e a t y<0
$$

Relating this to (1) means that:

$$
\partial S Q_{-} \text {bias }_{n} / \partial E n t r e a t y<0
$$


Accordingly with the inclusion of the entreaty, we expect that the numerical size of the ASC-SQ (in our case representing the utility of the ostomates' own ostomy pouch) and thereby SQ bias can be reduced, such that:

$$
\partial A S C_{S Q, n} / \partial E n t r e a t y<0 \rightarrow \partial S Q \_ \text {bias }_{n} / \partial E n t r e a t y<0
$$

Again, it is also important to see this framework in the light of the definition of the nonSQ ostomy pouches and the description of the hypothetical market where the respondents were explicitly told that, with the exception of the attributes in focus, the non-SQ pouches were identical to the respondents' present pouches. In principle, the respondents thus only make trade-offs with regards to the attributes and potential $S Q$ effects are cancelled-out as it enters the utility function for all three alternatives.

\section{Data}

The effect of the entreaty on potential SQ bias is tested in a Choice Experiment used to elicit preferences for changes in ostomy pouches among a sample of Swedish ostomates. We acknowledge that this is a group of respondents receiving a specific type of healthcare and that this could reduce the generalizability of the results. However, in a positive perspective, the high level of familiarity that the respondents have with the good being valued should have a positive influence on the validity of the stated preferences, all things being equal (List, 2003; List, 2004; Ladenburg, 2013).

Collection of data was carried out through a mailed survey consisting of 1,200 questionnaires. 600 respondents did not receive the entreaty (treatment A) whilst 600 respondents did (treatment B). Respondents were randomly sampled from a nationwide group of approximately 20,000 Swedish ostomates. Of the 1,200 questionnaires mailed to the respondents, 610 respondents returned the questionnaire. Of these, 145 respondents had an ostomy pouch without a filter ${ }^{4}$, which reduced the initial sample to 465 respondents. Of these, 211 respondents had stated protest preferences, reducing the effective sample to 254 usable responses ${ }^{5}$.

The distribution of effective responses between the two treatment groups was found to be similar, in that treatment A contained 116 responses and treatment $\mathrm{B}$ contained 138 responses. An analysis of a range of demographic background characteristics of the initial and effective samples is shown in Table 2.

\footnotetext{
${ }^{4}$ It should be noted that the study among other attributes focuses on the quality of the filter in an ostomy pouch. Accordingly, the survey was only relevant for ostomates that have an ostomy pouch with a filter. Unfortunately, we did not have prior information on whether or not the respondents had an ostomy pouch with a filter when the survey was carried out. The initial sample therefore includes respondents who have pouches without a filter. These respondents were not the target for the survey and were removed from the final sample.

${ }^{5}$ With regard to the distribution of protest preferences across treatment groups, it is shown in Bonnichsen and Ladenburg (2009), that respondents in treatment A have a significantly higher share of respondents with protest preferences compared to the respondents in treatment $\mathrm{B}$.
} 
Table 2: $\quad$ Respondent demographics compared across treatment groups (in \%)

\begin{tabular}{|c|c|c|c|c|c|c|}
\hline & \multicolumn{3}{|c|}{ Initial sample $(\mathrm{N}=465)$} & \multicolumn{3}{|c|}{ Effective sample ( $\mathrm{N}=\mathbf{2 5 4})$} \\
\hline & $\begin{array}{l}\text { Treat- } \\
\text { ment A } \\
(\mathrm{N}=223)\end{array}$ & $\begin{array}{l}\text { Treat- } \\
\text { ment B } \\
(\mathrm{N}=242)\end{array}$ & $\begin{array}{l}\text { Significance } \\
\text { in } \chi^{2} \text {-test }{ }^{a}\end{array}$ & $\begin{array}{l}\text { Treat- } \\
\text { ment A } \\
(\mathrm{N}=116)\end{array}$ & $\begin{array}{l}\text { Treat- } \\
\text { ment B } \\
(\mathrm{N}=138)\end{array}$ & $\begin{array}{l}\text { Significance } \\
\text { in } \chi^{2} \text {-test }\end{array}$ \\
\hline \multicolumn{7}{|l|}{ Gender } \\
\hline Male & 39 & 47 & \multirow{2}{*}{ * } & 40 & 51 & \multirow{2}{*}{$*$} \\
\hline Female & 61 & 53 & & 60 & 49 & \\
\hline \multicolumn{7}{|c|}{ Household gross income (SEK) } \\
\hline$<150,000$ & 12 & 12 & & 11 & 9 & \multirow{4}{*}{ NS } \\
\hline $150,000-299,999$ & 32 & 28 & \multirow{3}{*}{ NS } & 33 & 26 & \\
\hline $300,000-499,999$ & 32 & 33 & & 29 & 31 & \\
\hline$>500,000$ & 24 & 28 & & 27 & 34 & \\
\hline \multicolumn{7}{|l|}{ Age } \\
\hline $18-34$ & 6 & 6 & \multirow{3}{*}{ NS } & 9 & 7 & \multirow{3}{*}{ NS } \\
\hline $35-54$ & 33 & 27 & & 29 & 32 & \\
\hline $55-74$ & 61 & 67 & & 62 & 62 & \\
\hline \multicolumn{7}{|l|}{ Education } \\
\hline $\begin{array}{l}\text { Primary and } \\
\text { vocational }\end{array}$ & 75 & 72 & & 72 & 68 & \multirow{3}{*}{ NS } \\
\hline $\begin{array}{l}\text { Short-middle academic } \\
\text { (college) }\end{array}$ & 16 & 17 & \multirow[t]{2}{*}{ NS } & 16 & 19 & \\
\hline $\begin{array}{l}\text { Long-term academic } \\
\text { (university) }\end{array}$ & 9 & 10 & & 12 & 13 & \\
\hline \multicolumn{7}{|l|}{ Type of stoma ${ }^{b}$} \\
\hline Colostomy & 34 & 34 & \multirow{2}{*}{ NS } & 31 & 33 & \multirow{2}{*}{ NS } \\
\hline Ileostomy & 66 & 66 & & 69 & 67 & \\
\hline \multicolumn{7}{|c|}{ Length of time of stoma in place } \\
\hline$<1$ year & 1 & 0.5 & \multirow{4}{*}{ NS } & 1 & 1 & \multirow{4}{*}{ NS } \\
\hline $1-5$ years & 31 & 31 & & 31 & 35 & \\
\hline $5-10$ years & 27 & 26 & & 23 & 27 & \\
\hline$>10$ years & 42 & 41 & & 45 & 38 & \\
\hline \multicolumn{7}{|l|}{ Blocking } \\
\hline Block 1 & - & - & & 58 & 70 & \multirow[b]{2}{*}{ NS } \\
\hline Block 2 & - & - & & 58 & 75 & \\
\hline
\end{tabular}

NS indicates no significant difference at 95 percent level, * indicates a significant difference at 95 percent level.

${ }^{\mathrm{a}}$ The $\chi 2$-tests are employed on the basis of the actual numbers behind the percentages.

${ }^{b}$ There are three types of stoma: Colostomy, ileostomy, urostomy. The sample does not contain ostomates with urostomy. 
Table 2 reveals that the two treatment groups only differ significantly with respect to gender in both the initial and the effective samples ${ }^{6}$. With regard to the effective sample, women account for 40 percent of the total in treatment A whereas this share is 51 percent in treatment $\mathrm{B}^{7}$.

\section{Econometric specifications}

\subsection{Poisson model for count data}

Since we do not have revealed preference data information on the number of SQ choices and are therefore not able to directly observe SQ bias, we estimate a count data (Poisson) model with the number of SQ choices as the dependent variable in order to shed light on the level of potential SQ bias and to test the effect of the entreaty thereupon. The model uses respondent characteristics and the respondents' stated attribute levels for their own ostomy pouch as explanatory variables. Placing the SQ choice within the traditional framework for utility maximising behaviour, we expect the quality of respondents' own ostomy pouches to influence the choice of the SQ alternative significantly. Specifically, we expect that the higher quality a respondent's own pouch has in terms of longer filter lifetime and fewer leakages, the more frequently that respondent will choose the SQ alternative in a choice set. On the other hand, if the respondent's own pouch has a low quality in terms of short filter lifetime and many leakages, then we can expect the respondent to choose the SQ alternative less frequently and instead opt for one of the nonSQ alternatives. However, if choices are governed by SQ bias, we will expect a higher number of SQ choices and the abovementioned quality and SQ choice relations to be affected by SQ bias and consequently be less clear or potentially not present at all. The first approach to estimate the effect of the entreaty is therefore to empirically investigate which respondent characteristics and ostomy pouch attributes have an effect on the number of SQ choices.

The Poisson model is estimated using robust standard errors, which accounts for the under-dispersion of variance relative to the mean ${ }^{8}$. For details of the general model specification, refer to Greene (2008) and Verbeek (2008). In our Poisson models, the quality of the existing pouch attributes is represented by three dummy variables representing the number of leakages and two dummy variables representing filter lifetime. Starting with the former, Leaks10+, Leaks4_9 and Leaks2_3 represent the respondents who have stated that the number of monthly leakages of their own current pouch is 10 leakages or more, 4-9 leakages or 2-3 leakages, respectively. The reference category is fewer than two leakages per month. Filt0_3 and Filt4_12 represent the respondents having

\footnotetext{
${ }^{6}$ To test if the entreaty had an effect on the distributions of the various demographic background characteristics of the initial and effective samples (i.e. sampling bias), an analysis of whether the characteristics differ significantly between the initial and effective samples was also carried out. These $\chi^{2}-$ tests revealed that there were no significant differences between the characteristics of the initial and effective samples in both treatments. This would indicate that apart from the lower frequency of female respondents in treatment $\mathrm{A}$, there seems to be little selection into the two treatments from the initial to the effective sample. Results are available from the authors upon request.

${ }^{7}$ Due to the different distributions of gender in the two treatments, analyses were also carried out on a gender specific level. This approach was taken in order to ascertain whether potential differences with regard to the preferences of the respondents in the two treatments are caused merely by an overall impact of the entreaty or if there is a gender specific effect. The results of these analyses did not change the overall conclusions of the paper. Results are available from the authors upon request.

${ }^{8}$ We have also estimated a hurdle model, but with the exception of only a few variables, the differences in the parameters in the hurdle (logit) and count (Poisson) models were small and did not change the conclusions of the analysis.
} 
a pouch with a filter lifetime of three hours or less and one with 4-12 hours, respectively. The reference category here is a filter lifetime of more than 12 hours. Gender enters the model as a dummy variable controlling for whether the respondent is female or not, while the age and annual household income level of the respondent enter the model as continuous linear variables. The final socio-economic variables in the model are the dummy variables indicating whether the respondents have finished their education at primary school level (Edu_school) or have higher education (Edu_higher). The model also contains variables controlling for missing observations for socio-demographic variables or the stated quality of the respondents' own pouches'.

\subsection{Preference model}

The Poisson models for SQ choices do not reveal the individual trade-offs between the attribute levels of the respondent's own current pouch and the two non-SQ pouches. To shed light on the SQ bias problem in the frame of these preference relations, we analyse preferences using the Random Parameter Error Component Logit model and compare the preferences between the two treatments. The model relies on the random utility model (McFadden, 1974), which states that the true but ultimately unobservable utility $U$ of individual $n$ is broken down into two components, an observable systematic component $V$ and the unobservable random component, the error term $\varepsilon$. Individual $n$ 's true utility for the $i$ th alternative can be written:

$$
U_{n i}=V_{n i}\left(x_{n i}, S_{n}, \beta\right)+\varepsilon_{n i}
$$

Where the observable component $V_{n i}$ is a function of the attributes of the alternatives $x_{n i}$, characteristics of the individuals $S_{n}$ and a set of unknown preference parameters $\beta$. The observable component $V_{n i}$ is assumed to be a linear function:

$$
V_{n i}=A S C+\beta_{m} x_{m i}
$$

In (6) $\beta$ denotes a vector of preference parameters associated with attribute $m, x_{m i}$ a vector of attributes of alternative $i$ and $A S C$ denotes an alternative specific constant (ASC). In this paper, the ASC represents the respondents own pouch system, i.e. ASC-SQ. The ASC-SQ thus expresses the utility associated with the SQ alternative (the respondents own ostomy pouch) relative to the two non-SQ alternatives. This utility is attributed to the SQ alternative in itself and cannot be explained by other explanatory variables in the model ${ }^{10}$. The SQ is defined by the current system of the individual instead of using a zero coded or effects coded SQ. This approach eliminates the need for effects coding the attributes to be able to interpret the ASC. Accordingly, the estimated ASC-SQ parameter captures the utility of the SQ alternative while controlling for the quality attributes of the respondent's

\footnotetext{
${ }^{9}$ Socio_miss is a joint variable that controls for respondents having a missing observation for at least one of the tested socio-demographic variables. Variables that control for missing observations for the specific socio-demographic variables have also been tested, but due to low numbers and correlation issues, a joint variable was deemed to be most suitable. Having a joint control variable for missing information does not influence the results of the variables related to the satisfaction and quality of the respondents' present ostomy pouch. Current_Filt_miss controls for respondents, who have not stated a filter lifetime for their ostomy pouch. All respondents have stated a frequency of leakages from their pouch.

${ }^{10}$ According to Meyerhoff and Liebe (2009) the interpretation of the ASC parameter depends on whether one sees it mainly as a technical parameter (capturing the average effect of all relevant factors that are not included in the model) or associates the ASC parameter with a behavioural assumption. As suggested by Adamowicz et al. (1998), we choose the latter approach and interpret the ASC-SQ as the utility of the SQ alternative.
} 
own ostomy pouch, through the estimated ostomy pouch attributes. This should clean the ASC-SQ for any SQ effects so that only SQ bias is investigated.

The observable part of utility can be specified as the indirect utility function, using the attributes of the present study:

$$
V_{n i}=\beta_{\text {ASC }} \times d_{\text {ASC }}+\beta_{\text {leaks }} \times d_{\text {leaks }}+\beta_{\text {filtlife }} \times d_{\text {filtlife }}+\beta_{\text {flex }} \times d_{\text {flex }}+\beta_{\text {price }} \times \text { price }
$$

Where price is coded as linear and continuous and the other attributes are dummy-variable coded. By including a monetary attribute, it is possible to estimate WTP for the nonmonetary attributes. This is done by scaling the coefficient of interest with the coefficient representing the marginal utility of price and multiplying by -1 (Louviere et al., 2000):

$$
W T P_{x}=-\frac{\beta_{x}}{\beta_{\text {price }}}
$$

Where $\beta_{x}$ is the coefficient of the attribute of interest and $\beta_{\text {price }}$ is the price coefficient.

The dependent variable in the preference model is the choice among the SQ alternative and the two non-SQ alternatives. Assuming a specific parametric distribution of the error term allows a probabilistic analysis of individual choice behaviour:

$$
\operatorname{Prob}_{n i}=\operatorname{Prob}\left(V_{n i}+\varepsilon_{n i} \geq V_{n j}+\varepsilon_{n j}\right) \forall i, j \in C, j \neq i
$$

Where $\operatorname{Prob}_{n i}$ is the probability that individual $n$ 's utility is maximised by choosing alternative $i$ from choice set $C$. If the error terms are assumed to be independently and identically Gumbel distributed, then this results in a Conditional Logit specification for the probability of individual $n$ choosing alternative $i$ :

$$
\operatorname{Prob}_{n i}=\frac{e^{V_{n i}}}{\sum_{\mathrm{j} \in \mathrm{C}} e^{V_{n j}}}
$$

Where the scale parameter is normalised to 1, and omitted. The Conditional Logit model imposes several restrictive assumptions in that it does not allow for random taste variation, for unrestricted substitution patterns and for correlation in unobserved factors over time (Train, 2003). The model also suffers from having to adhere to the restrictive Independence of Irrelevant Alternatives property. Due to these restrictions, the Conditional Logit model may be unsuitable for identifying a possible SQ bias and other models that avoid some of these restrictions should be considered.

To extend the Conditional Logit model, an additional error component is incorporated into the model to capture any remaining SQ effects in the stochastic part of utility (Scarpa et al., 2005). The additional error component has zero-mean and is a normally distributed random parameter assigned only to the two non-SQ alternatives. Following Meyerhoff and Liebe (2009), the utility function of the error component logit specification can be written as:

$$
U_{n i}=V_{n i}+E_{n i}+\varepsilon_{n i}
$$

Where $V_{n i}$ is the systematic component of utility, $E_{n i}$ are the error components and $\varepsilon_{n i}$ is the same Gumbel distributed error term from the Conditional Logit model. By including the additional error components, the Independence of Irrelevant Alternatives restriction is 
eliminated and any remaining systematic effect of the SQ is captured by the ASC-SQ (Scarpa et al., 2005), as described previously.

\section{Random parameter error component logit}

To further extend the model, the Random Parameter Error Component Logit specification is applied. The specification allows for taste heterogeneity in preferences by specifying some or all attribute coefficients as random. The model allows for correlation in unobserved utility over alternatives and time (Train, 2003). Here individual $n$ 's true utility for the $i$ th alternative can be rewritten as:

$$
U_{n i}=V_{n i}^{\prime}\left(x_{n i}, \beta, \beta_{n}\right)+E_{n i}+\varepsilon_{n i}
$$

Where $\beta_{n}$ denotes individual specific random parameters while $\beta$ denotes the fixed parameters and the characteristics of the individuals are left out for simplicity. The model is specified with the ASC-SQ and the price coefficient being fixed and all other coefficients being normally distributed. Assuming that the error term is still Gumbel distributed, the probability of individual $n$ choosing alternative $i$ can be written:

$$
\operatorname{Prob}_{n \mathbf{i}}=\int\left(\frac{e^{V_{n i}^{\prime}+E_{n i}}}{\sum_{\mathbf{j} \in \mathrm{C}} e^{V_{n j}^{\prime}+E_{n j}}}\right) \phi(\beta \mid b, W) d \beta
$$

Where $\phi(\beta \mid b, W)$ is the normal density with mean $b$, covariance $W$ and $\mathbf{i}$ is a sequence of alternatives, one for each choice occasion, $\mathbf{i}=\left\{i_{1}, \ldots, i_{T}\right\}$, where $T$ is the total number of choice occasions. In this way, the model allows for the panel structure of the Choice Experiment data by allowing for the utility coefficients to vary over individuals but remain constant over $T$ choice occasions for each individual (Train, 2003).

The test of the entreaty's effect on SQ bias and preferences is carried out by comparing the estimated levels of WTP and by carrying out a test of equality of preferences via a Likelihood Ratio test for nested models (Swait and Louviere, 1993).

\section{Results and discussion}

\subsection{Poisson models}

Table 3 shows how the number of SQ choices is influenced by the quality of the respondents' own current ostomy pouches in terms of filter lifetime and the number of leakages.

As the results suggest, the preferences of the treatment group not given the entreaty (treatment A) appear to be governed by SQ bias. In treatment A, the estimated parameters for the dummy variables coding for the number of leakages and filter lifetime are not significantly different from the reference category. The estimated parameters $\beta_{\text {Leaks } 10+}$ and $\beta_{\text {Leaks_ } 9}$ are negative and thus have the expected sign regarding the influence on the number of SQ choices. As it cannot be rejected that $\beta_{\text {Leaks } 2_{-3}}=\beta_{\text {Leaks } 4_{-} 9}=\beta_{\text {Leaks10+ }}$, this strongly indicates that the number of leakages of the respondents' own current pouch does not influence the number of SQ choices. Similarly, the two estimated parameters controlling for the filter lifetime both have the wrong sign (positive) and $\beta_{\text {Filt_ }} 12$ is even significant. This suggests that respondents in treatment A whose current pouch has a filter lifetime between 4-12 hours more frequently choose the SQ alternative compared to respondents whose present pouch has a filter lifetime that is longer. 
Table 3: $\quad$ Poisson models (dependent variable: Number of SQ choices)

\begin{tabular}{lll}
\hline & Treatment A & Treatment B \\
\hline Constant & $-0.51(0.5)$ & $0.79^{*}(0.32)$ \\
Leaks10+ & $-0.25(0.19)$ & $-0.59^{* *}(0.21)$ \\
Leaks4_9 & $-0.094(0.0979)$ & $-0.41^{* *}(0.15)$ \\
Leaks2_3 & $0.014(0.0849$ & $0.046(0.096)$ \\
Filt0_3 & $0.05(0.21)$ & $-0.45^{*}(0.29$ \\
Filt4_12 & $0.26^{+}(0.15)$ & $-0.18(0.12)$ \\
Gender & $-0.041(0.076)$ & $0.23^{*}(0.095)$ \\
Age & $-0.0009^{* * *}(0.0002)$ & $-0.0003^{* *}(0.0001)$ \\
Income & $0.023(0.017)$ & $0.0037(0.017)$ \\
Edu_school & $-0.14^{* * *}(0.04)$ & $-0.073(0.053)$ \\
Edu_higher & $0.01(0.032)$ & $-0.017(0.037)$ \\
Socio_miss & $0.17(0.15)$ & $0.019(0.14)$ \\
Current_filt_miss & $0.11(0.18)$ & $0.38^{*}(0.19)$ \\
\hline$N$ & 117 & 143 \\
LL(0) & -220.4 & -279.8 \\
LL(b) & -211.2 & -263.1 \\
$\chi^{2}$ & 41.43 & 35.27 \\
\hline Standard errors & &
\end{tabular}

Standard errors in brackets. ${ }^{+}$indicates significance at 90 per cent level, ${ }^{*}$ at 95 per cent level, ${ }^{* *}$ at 99 per cent level and ${ }^{* * *}$ at 99.9 per cent level.

Therefore, despite the fact that a filter lifetime of 0-3 hours is substantially worse, compared to a filter lifetime of more than 12 hours (the reference category), the number of times the SQ alternative is chosen appears to be independent of these differences. Therefore, across the two types of quality attributes, we do not observe the expected relation between the decreasing quality of the existing pouch and the number of choices among non-SQ alternatives, suggesting that other motives have an influence on the SQ choices of the respondents in treatment group A.

Moving on to the model for the treatment group given the entreaty (treatment B), the results show a completely different picture. The choice frequency of the SQ alternative in this treatment group is significantly dependent on the quality of the respondent's current ostomy pouch both in terms of the number of leakages as well as filter lifetime. Respondents with an ostomy pouch that leaks more than three times per month choose the SQ alternative significantly less frequently $\left(\beta_{\text {Leaks } 10+}\right.$ and $\beta_{\text {Leaks } 49}$ are negative). The marginal effect is $1.68\left(\beta_{\text {Leaks10+ }}\right)$ and $1.14\left(\beta_{\text {Leaks__9 }}\right)$ fewer SQ choices compared to respondents with a pouch that leaks less than twice a month. The estimated parameters $\beta_{\text {Leaks4_9 }}$ and $\beta_{\text {Leaks } 10+}$ are not significantly different from each other. The parameter estimate of the third leakage dummy variable, $\beta_{\text {Leaks2 } 3}$ is positive and not significant. Both $\beta_{\text {Leaks } 49}$ and $\beta_{\text {Leaks } 10+}$ are significantly different from $\beta_{\text {Leaks2_3 }}$ on a 99 per cent level of confidence. Moving on to the estimated parameters for the two filter lifetime quality dummy variables, $\beta_{\text {Filto_ } 3}$ is significant and with the expected negative sign. In marginal terms, respondents with a present ostomy pouch that has a filter that only functions between zero and three hours choose the SQ alternative 1.27 fewer times than respondents whose pouch has a 
filter lifetime longer than twelve hours. $\beta_{\text {Filt__12 }}$ is not significant but has the expected negative sign.

The results from the Poisson models strongly indicate that the respondents who did not receive the entreaty seem to have other and stronger motives for choosing the SQ alternative than the quality of their own current ostomy pouch. As argued, we suspect this to be a payment based protest attitude. On the other hand, the respondents who received the entreaty have chosen the SQ alternatives in accordance with the expected utility maximising behaviour (i.e. when they have higher quality attributes of their present pouch, they choose the SQ alternative more often and vice versa).

\subsection{Preference models}

In this section, the effect of the entreaty on SQ bias is tested using the Random Parameter Error Component Logit model as shown in Table 4. WTP is in SEK per month.

The results from Table 4 show that when controlling for the influence of the attributes in the alternatives on the choices, the WTP for the SQ via $\mathrm{WTP}_{\mathrm{ASC}-\mathrm{SQ}}$ is considerably reduced by the entreaty. In treatment A, WTP $\mathrm{ASC}-\mathrm{SQ}$ is 545 , whilst it is 197 in treatment $\mathrm{B}$. This difference is significant on a 95 per cent level, indicating that the entreaty has lowered the preferences for the SQ alternative. In other words, the introduction of the entreaty has reduced the utility threshold associated with the SQ alternative. This change in the WTP is not governed by a uniform increase in the WTP for other attributes in treatment B. On the contrary the WTPs generally appear to be relatively constant with the exception of the difference in $\mathrm{WTP}_{\mathrm{FLEX}-\mathrm{s}}$ being the only significant WTP difference in the other attributes. Equality of preferences can also be formally tested by investigating the effects of the entreaty on overall preferences via a Likelihood Ratio test for nested models (Swait and Louviere, 1993). The Likelihood Ratio test statistic in the last row of Table 4, indicates that the respondents in the two treatments have, on a 95 per cent level of significance, stated identical preferences on an overall level.

Although models used in rational choice theory are diverse, all assume individuals choose the best action according to stable preference functions and constraints facing them. A standard assumption in economic theory is that more is preferred to less. Without any biases this relation is expected to also emerge in stated preferences for hypothetical goods. However, if the preferences are governed by an unwarranted (and strong) tendency to choose the SQ alternative, this might weaken the otherwise rational preference ordering. In the present application, a rational preference ordering should induce the respondents to have stronger preferences for no leakages per month compared to one leakage per month, a filter life time of 24 hours compared to 12 hours and a pouch system which has a large improvement in flexibility compared to a small improvement in flexibility. Looking at the estimated coefficients from the treatment group not given the entreaty (treatment A), it seems that the rational preference structure mentioned above is not generally present. More specifically, preferences for a filter with a lifetime of 24 hours or a pouch system with large flexibility are preferred less than a filter with a lifetime of 12 hours or a pouch system with small flexibility, respectively. Though these differences are not significant, they suggest that the respondents on average have not traded rationally between the SQ and the filter lifetime and flexibility attributes. Again, this suggests that other elements have entered their choice function, which we argue could be grounded in payment based protest attitudes. As elaborated upon on in the Poisson model results, the dominance of the SQ alternative seems be one of these elements, indicating SQ bias. 
Table 4: $\quad$ Preference models (dependent variable: Choice of ostomy pouch)

\begin{tabular}{|c|c|c|c|}
\hline & Treatment A & Treatment B & \\
\hline \multicolumn{4}{|c|}{ Mean estimates } \\
\hline ASC_SQ & $3.00^{* * *}(0.57)$ & $1.34^{* *}(0.49)$ & \\
\hline Leaks_1 & $1.45^{* * *}(0.47)$ & $1.27^{* * *}(0.38)$ & \\
\hline Leaks_0 & $3.01^{* * *}(0.43)$ & $2.42^{* * *}(0.43)$ & \\
\hline Filt_12 & $0.66(0.4)$ & $0.56(0.34)$ & \\
\hline Filt_24 & $0.63(0.43)$ & $1.15^{* * *}(0.37)$ & \\
\hline Flex_S & $1.55^{* *}(0.48)$ & $0.55(0.4)$ & \\
\hline Flex_L & $1.45^{* *}(0.47)$ & $0.68(0.42)$ & \\
\hline Price & $-0.0055^{* * *}(0.0009)$ & $-0.0068^{* * *}(0.0011)$ & \\
\hline \multicolumn{4}{|c|}{ Standard deviation } \\
\hline Leaks_1 & $0.03(0.55)$ & $0.24(0.74)$ & \\
\hline Leaks_0 & $0.0069(0.67)$ & $1.56^{* *}(0.54)$ & \\
\hline Filt_12 & $0.12(0.92)$ & $0.076(0.6)$ & \\
\hline Filt_24 & $0.1(1.63)$ & $0.96(0.6)$ & \\
\hline Flex_S & $0.063(0.72)$ & $0.073(0.54)$ & \\
\hline Flex_L & $0.12(0.85)$ & $1.73^{* * *}(0.49)$ & \\
\hline EC_12 & $2.53^{* * *}(0.39)$ & $3.40^{* * *}(0.56)$ & \\
\hline WTP & & & $\Delta \mathrm{WTP}\left[\mathrm{T}-\mathrm{value}^{\mathrm{a}}\right]$ \\
\hline ASC_SQ & $545^{* * *}(139.97)$ & $197^{*}(81.56)$ & $350^{*}[2.15]$ \\
\hline Leaks_1 & $264^{* *}(100.52)$ & $187^{* *}(58.06)$ & $78[0.66]$ \\
\hline Leaks_0 & $547^{* * *}(98.95)$ & $356^{* * *}(57.78)$ & 193 [1.67] \\
\hline Filt_12 & $119(67.2)$ & $82(48.8)$ & 38 [0.46] \\
\hline Filt_24 & $115(73.35)$ & $169^{* * *}(50.88)$ & $-54[-0.61]$ \\
\hline Flex_S & $282^{* * *}(80.71)$ & $80(56.77)$ & $203^{*}[2.04]$ \\
\hline Flex_L & $264^{* * *}(79.81)$ & $99(60.44)$ & $164[1.64]$ \\
\hline Observations & 505 & 621 & \\
\hline Halton draws & 1000 & 1000 & \\
\hline $\mathrm{LL}(\mathrm{b})$ & -256.2 & -381.6 & \\
\hline Adj. $R^{2}$ & 0.511 & 0.419 & \\
\hline LR-test (DF) & $26.1(16)$ & & \\
\hline
\end{tabular}

Standard errors in brackets. ${ }^{*}$ indicates significance at 95 per cent level, ${ }^{* *}$ at 99 per cent level and ${ }^{* * * *}$ at 99.9 per cent level.

${ }^{a}$ An asymptotic t-test of the significance of the differences in WTP. Standard errors for WTP are estimated using the Delta Method in accordance with Greene (2008) and Hanemann and Kanninen (1999).

Interestingly, in the treatment group given the entreaty (treatment B), a filter with a lifetime of 24 hours or a pouch system with large flexibility is preferred more than a filter with a lifetime of 12 hours or a small flexibility, respectively. Accordingly, the entreaty seems to have influenced the rationality in the preference structure and thereby reduced the effect of the SQ bias on preference ordering. 
The most important attribute level for the average respondent is a system with no leakages. With this in mind it is worth focusing on the WTP estimates for the no leakages attribute and the ASC-SQ. In treatment A the $\mathrm{WTP}_{\mathrm{ASC}-\mathrm{SQ}}$ is 545 and is thus nearly identical to the WTP for the no leakage attribute. Stated differently, on an average level in treatment $\mathrm{A}$, when confronted with the choice between a pouch that does not leak and their existing pouch, the average respondent will be indifferent. This is due to the strong preference for the SQ as shown by the magnitude of the ASC-SQ. Moving on to treatment $\mathrm{B}$, the relative preferences between the SQ alternative and the other attributes are different. In treatment B the WTP estimates for no leakages is 80 per cent higher than $\mathrm{WTP}_{\mathrm{ASC}-\mathrm{SQ}}$. The difference between $\mathrm{WTP}_{\mathrm{ASC}-\mathrm{SQ}}$ and all of the other attributes has also been considerably reduced, making the preferences for the SQ alternative less dominant relative to the improvement attributes.

Finally, it should be noted that the respondents in treatment B appear to generally have lower levels of WTP compared to the respondents in treatment A. Accordingly, wording used in the entreaty to soften up the perception of the payment attribute, combined with the reminder to "carefully consider the hypothetical expense, as if you were to pay it when making your choices", seems to have made the respondents more cost sensitive. As commented on by one reviewer, we could have suspected the opposite. The entreaty could have influenced the perception of the cost attribute and made the respondents pay less attention to the cost attribute and potentially even perceive it on an ordinal scale. However, this does not seem to be the case.

\subsection{Reduction of status quo bias}

The aim of our analysis is to verify if the entreaty is able to reduce SQ bias in the stated preferences, which is suspected to be induced by payment based protest attitudes. Ideally revealed preference data should be available in order to compare the level of SQ choices in survey data (with and without the entreaty) with the corresponding level of SQ choices on the real market, thereby directly testing the effect on the entreaty on SQ bias ${ }^{11}$. Unfortunately, such ostomy pouch data is to the authors' knowledge not available. However, as our analysis of which covariates influence the number of SQ choices among the bundle of two hypothetical alternatives and the ostomates' own ostomy pouch (SQ alternative) suggests, there seems to be suitable grounds for believing that our stated preference data is influenced by SQ bias. The essence of our results from both the Poisson and preference models is that the entreaty seems to have an impact on the stated preferences on several levels. First of all, without the entreaty, the preference ordering is not satisfactory from a theoretical point of view. Secondly, without the entreaty, the Poisson and preference models show that the relative preferences for the SQ alternative compared to the attribute improvements is so strong, that the respondents are indifferent to having their present ostomy pouch and an improved pouch. The inclusion of the entreaty seems to remedy these issues simultaneously. Referring back to the relation between a payment based protest attitude and SQ bias, these results suggest that without the entreaty, some choices might be governed by payment based protest attitudes, which makes respondents tend to choose the SQ alternative without actually paying much attention to the attributes of the non-SQ ostomy pouch alternatives per se. It would appear that the entreaty might be able to reduce the level of payment based protest attitudes and induce

\footnotetext{
${ }^{11}$ Similarly, the effect of the entreaty should also be tested across several Choice Experiment surveys in order to estimate the general effect of the entreaty. However, it was not within the frame of the present study to carry out several Choice Experiment surveys when data was collected. It was thus only possible to test the effect of the entreaty in a single study.
} 
the respondents to make more considered choices in this relation. When presented with the entreaty, the non-SQ alternatives are chosen more frequently and in the choice among the alternatives, the respondents choose an improvement of their ostomy pouch in a theoretically systematic manner. Jointly, these results strongly indicate that the stated preferences in treatment A to a higher extent are governed by SQ bias, which, as argued, is suspected to be grounded in payment based protest attitudes and that this protest attitude and SQ bias is reduced in treatment B via the entreaty.

\section{Conclusion}

The aim of this paper was to test if the threshold for choosing a hypothetical alternative that exists in stated preference surveys (i.e. a status quo bias), can be reduced by the use of a short and simple entreaty. The entreaty is presented to respondents prior to the actual choice situation and is designed to reduce payment based protest attitudes. Applying a health economic Choice Experiment case of Swedish ostomates' preferences for ostomy pouch quality changes and a two-split sample design, we firstly find that the entreaty leads to a more stable preference ordering that conforms to economic theory. Secondly, the respondents not presented with the entreaty have a dominant preference for the status quo (SQ) and their propensity to choose the SQ alternative seems to be independent of the quality of their own present ostomy pouch. In other words, respondents with a low quality pouch, where it can be expected that they choose a non-SQ alternative more often, still choose the SQ alternative just as frequently as those with a high quality present pouch. These preferences do not seem to conform to economic theory and the expected relation between respondents' own ostomy pouch quality and the number of choices of the SQ alternative. Taken together, this is all a strong indication of the presence of SQ bias, which is argued to be governed by payment based protest attitudes. Those respondents who were presented with the entreaty do not show these dominant preferences for the SQ alternative and we find the expected relation, in that the higher quality the respondents' own ostomy pouch has, the higher is the number of SQ alternative choices and vice versa. These results could lead one to expect that the respondents presented with the entreaty might exhibit exaggerated marginal preferences for the attributes of the hypothetical alternatives compared to the SQ (i.e. hypothetical bias), but this has not been observed. Instead, the marginal demand for the attributes appears to have been reduced. This suggests that that the use of the entreaty has in this case been an easy-to-implement and effective method to reduce SQ bias.

\section{Acknowledgements}

We gratefully acknowledge Coloplast A/S for providing financial support. The authors would also like to thank the Danish Institute for Local and Regional Government Research (KORA) for funding the completion of this paper and two anonymous reviewers as well as the journal editor for many constructive comments. Any errors remaining are, of course, the sole responsibility of the authors.

\section{References}

Aadland, D., Caplan, A.J. (2003). Willingness to pay for curbside recycling with detection and mitigation of hypothetical bias. American Journal of Agricultural Economics, 85, 492-502.

Aadland, D., Caplan, A.J. (2006). Cheap talk reconsidered: New evidence from CVM. Journal of Economic Behavior and Organization, 60, 562-578. 
Adamowicz, W.L., Boxall, P., Williams, M., Louviere, J. (1998). Stated Preference Approaches to Measuring Passive Use Values: Choice Experiments versus Contingent Valuation. American Journal of Agricultural Economics, 80(1), 64-75.

Ami, D., Aprahamian, F., Chanel, O., Luchini, S. (2011). A Test of Cheap Talk in Different Hypothetical Contexts: The Case of Air Pollution. Environmental and Resource Economics, 50, 111-130.

Banzhaf, M.R., Reed, F.R., Mathews, K.E. (2001). Opt-Out Alternatives and Anglers' Stated Preference. In J. Bennett and R. Blamey (Eds.), The Choice Modeling Approach to Environmental Valuation. Northampton, MA: Edward Elgar Publishing.

Barrage, L., Lee, M.S. (2010). A penny for your thoughts: Introducing truth-telling in stated preference elicitation. Economic Letters, 106, 140-142.

Blumenschein, K., Blomquist, G.C., Johannesson, M., Horn, N., Freeman, P.R. (2008). Eliciting willingness to pay without bias: evidence from a field experiment. Economic Journal, 118: 114137.

Bonnichsen, O. (2011). Elicitation of Preferences for Improvements in Ostomy Pouches - A Discrete Choice Experiment. Patient, 4(3), 163-175.

Bonnichsen, O., Ladenburg, J. (2009). Using an Ex-ante Entreaty to Reduce Protest Zero Bias in Stated Preference Surveys - A Health Economic Case. Journal of Choice Modelling, 2(2), 200-215.

Bosworth, R., Taylor, L. (2012). Hypothetical bias in Choice experiments: Is Cheap Talk effective at lemiminating bias on the intensive and extensive margins of choice? The B.E. Journal of Economic Analysis \& Policy, 12, 1935-1682.

Boxhall, P., Adamowicz, W., Moon, A. (2009). Complexity in choice experiments: choice of the status quo alternative and implication for welfare measurement. The Australian Journal of Agricultural and Resource Economics, 53(4), 503-519.

Carlsson, F., Martinsson, P. (2001). Do Hypothetical and Actual Marginal Willingness to Pay Differ in Choice Experiments? Journal of Environmental Economics and Management, 41(2), 179-192.

Carlsson, F., Martinsson, P., Akai, A. (2011). The effect of power outages and cheap talk on willingness to pay to reduce outages. Energy Economics, 33(5), 790-798

Chapman, G.B., Li, M., Colby, H., Yoon, H. (2010). Opting in vs opting out of influenza vaccination. JAMA, 304, 43-44.

Cummings, R.G., Taylor, L.O. (1999). Unbiased value estimates for environmental goods: A cheap talk design for the contingent valuation method. American Economic Review, 89(3), 649-665.

Greene, W.H. (2008). Econometric Analysis. Upper Saddle River, New Jersey: Pearson Prentice Hall.

Hanemann, M.W, Kanninen, B. (1999). The statistical analysis of discrete-response CV data. In I.J. Bateman and K.G. Willis (Eds.), Valuing Environmental Preferences. Theory and Practice of the Contingent Valuation Method in the US, EU and Developing Countries. Oxford University Press, Oxford.

Johnson, E.J., Goldstein, D. (2003). Do Defaults Save Lives? Science, 302, 1338-1339.

Kahneman, D., Knetsch, J.L., Thaler, R.H. (1991). The Endowment Effect, Loss Aversion, and Status Quo Bias: Anomalies. Journal of Economic Perspectives, 5(1), 193-206.

Kataria, M., Bateman, I., Christensen, T., Dubgaard, A., Hasler, B., Hime, S., Ladenburg, J., Levin, G., Martinsen, L., Nissen, C. (2012). Scenario realism and welfare estimates in choice experiments - A 
non-market valuation study on the European water framework directive. Journal of Environmental Management, 94, 25-33.

Kuhfeld, W.F. (2010). Marketing research methods in SAS: experimental design, choice, conjoint and graphical techniques. Cary (NC): SAS Institute Inc.

Ladenburg, J., Bonnichsen, O., Dahlgaard, J.O. (2011). Testing the effect of a short Cheap Talk Script in Choice Experiments. Danish Journal of Economics (Nationaløkonomisk Tidsskrift), 149, 25-54.

Ladenburg, J. (2013). Does gender-specific starting point bias in Choice Experiments prevail among well informed respondents: Evidence from an empirical study. Applied Economic Letters, 20(7), 1527-1530.

Ladenburg, J., 2014. Out of sight, out of the constrained mind: Testing the effect of a Cheap Talk in Choice Experiments, USAEE Working Paper No. 13-153.

Ladenburg, J., Olsen, S.B. (2014). Augmenting short cheap talk scripts with a repeated opt-out reminder in choice experiment surveys. Resource and Energy Economics 37, 39-63

Lancaster, K.J. (1966). A new Approach to Consumer Theory. Journal of Political Economy, 74, 132157.

List, J.A. (2001). Do explicit warnings eliminate the hypothetical bias in elicitation procedures? Evidence from field auctions for sportscards. American Economic Review, 91, 1498-1507.

List, J.A., Gallet, C.A. (2001). What experimental protocol influence disparities between actual and hypothetical stated values. Environmental and Resource Economics, 20(3), 241-254.

List, J. A. (2003). Does market experience eliminate market anomalies? Quarterly Journal of Economics, 118(1), 41-71.

List, J.A. (2004). Neoclassical theory versus prospect theory: Evidence from the Marketplace, Econometrica, 72(2), 615-625.

Louviere, J.J., Lancsar, E. (2009). Choice experiments in health: the good, the bad, the ugly and toward a brighter future. Health Economics, Policy and Law, 4(4), 527-546.

Louviere, J.J., Hensher, D.A., Swait, J.D. (2000). Stated Choice Methods, Analysis and Application. Cambridge: Cambridge University Press.

Lusk, J.L. (2003). Effects of cheap talk on consumer willingness-to-pay for golden rice. American Journal of Agricultural Economics, 85, 840-856.

McFadden, D. (1974). Conditional logit analysis of qualitative choice behaviour. In P. Zarembka (Eds.), Frontiers in Econometrics. New York: Academic Press Inc.

Mahieu, P.A. (2010). Does gender matter when using cheap talk in contingent valuation studies? Economics Bulletin, 30(4), 1-7.

Meyerhoff, J., Liebe, U. (2009). Status quo effects in Choice Experiments: Empirical evidence on attitudes and choice task complexity. Land Economics, 85(3), 515-528.

Morrison, M., Brown, T.C. (2009). Testing the effect of certainty scales, cheap talk and dissonanceminimization in reducing hypothetical bias in Contingent Valuation studies. Environmental Resource Economics, 44, 307-326.

Nayga R.M. Jr., Woodward R., Aiew W. (2006). Willingness to pay for reduced risk of foodborne illness: a nonhypothetical field experiment. Canadian Journal of Agricultural Economics, 54, 461475 . 
Nugent, K.P., Daniels, P., Stewart, B. (1999). Quality of life in stoma patients. Diseases of the Colon and Rectum, 42, 1569-74

Ozdemir, S., Johnson, F.R., Hauber, A.B. (2009). Hypothetical bias, cheap talk, and stated willingness to pay for health care. Journal of Health Economics, 28(4), 894-901.

Probst, C.A., Shaffer, V.A., Chan, Y.R. (2013). The effect of defaults in an electronic health record on laboratory test ordering practices for pediatric patients. Health Psychology, 32, 995-1002.

Samuelson, W., Zeckhauser, R. (1988). Status Quo Bias in Decision Making. Journal of Risk and Uncertainty, 1(1), 7-59.

Silva, M.A., Ratnayake, G., Deen, K.I. (2003). Quality of life of stoma patients: temporary ileostomy versus colostomy. World Journal of Surgery, 27, 421-4

Scarpa, R., Ferrini, S., Willis, K. (2005). Performance of Error Component Models for Status-Quo Effects in Choice Experiments. In R. Scarpa and A. Alberini (Eds.), Applications of Simulation Methods in Environmental and Resource Economics. The Economics of non-Market Goods and Resources 6. Dordrecht, Netherlands: Springer.

Swait, J., Louviere, J. (1993). The role of the scale parameter in the estimation and comparison of multinomial logit models. Journal of Marketing Research, 30(3), 305-314.

Train, K. (2003). Discrete Choice Methods with Simulation. Cambridge: Cambridge University Press.

Vanleene, V., De Maré, L., Moldenaers, I., Debruyne, H., Simoens, S., Van den Steen, D., Ramaekers, D. (2008). Estimation and comparison of ostomy appliance costs with tariffs in Belgium. European Journal of Health Economics, 9(1), 17-22.

Verbeek, M. (2008). A Guide to Modern Econometrics. West Sussex, England: John Wiley \& Sons.

Zwerina, K., Huber, J., Kuhfeld, W. (2010). A general method for constructing efficient choice designs. Cary (NC): SAS Institute Inc.

(C) 2015 the author(s). This article is an open access article distributed under the terms and conditions of the Creative Commons Attribution license (http://creativecommons.org/licenses/by/4.0/). 